\title{
Radical Trachelectomy
}

National Cancer Institute

\section{Source}

National Cancer Institute. Radical Trachelectomy. NCI Thesaurus. Code C136288.

Surgical removal of the uterine cervix and pelvic lymph nodes. 